\title{
EVIDÊNCIAS DO EMPREENDEDORISMO INTERNO EM ORGANIZAÇÕES NO CONTEXTO DA INOVAÇÃO
}

\section{1- Magnus Luiz Emmendoerfer*}

Doutor em Sociologia e Política pela Universidade Federal de Minas Gerais - UFMG, Belo Horizonte/MG, Brasil. Professor do Departamento de Administração da Universidade Federal de Viçosa - UFV, Viçosa/MG, Brasil. magnus@ufv.br

http://lattes.cnpq.br/0919407313173824

\section{2- Josiel Lopes Valadares}

Graduado em Administração pela Universidade Federal de Viçosa - UFV, Viçosa/MG, Brasil. adm_josiel@yahoo.com.br

http://lattes.cnpq.br/4460783445382011

\section{3- Marcos Hashimoto}

Doutor em Administração de Empresas pela Fundação Getulio Vargas - FGV, São Paulo/SP, Brasil.

Professor do Mestrado Profissional da Faculdade Campo Limpo Paulista - FACCAMP, Campo Limpo Paulista/SP, Brasil marcosh@insper.edu.br

http://lattes.cnpq.br/8655211749535634 


\title{
EVIDÊNCIAS DO EMPREENDEDORISMO INTERNO EM ORGANIZAÇÕES NO CONTEXTO DA INOVAÇÃO
}

\section{RESUMO}

Este trabalho é um ensaio teórico resultante de uma pesquisa no Brasil sobre a construção do conhecimento em empreendedorismo. Tem como objetivo identificar e discutir as evidências do empreendedorismo interno, tomando como base dois elementos empíricos, o "Intraempreendedorismo" e o "Empreendedorismo Corporativo" em organizações no contexto da inovação. Em termos metodológicos, as fontes de dados foram essencialmente secundárias, tomando como base principal a produção técnicacientífica sobre o objeto em estudo. Fez-se uso de princípios de meta-análise e da técnica de análise de conteúdo que permitiram observar diferenças entre o Intraempreendedorismo e o Empreendedorismo Corporativo em termos organizacionais e comportamentais. Dentre os resultados principais, percebe-se enquanto reflexões necessárias no campo, a necessidade de clarificação dos elementos que distinguem os empreendedores corporativos dos intraempreendedores nas organizações, bem como compreender os elementos que estimulam comportamentos voltados ao empreendedorismo interno. Dentre os comportamentos mais evidenciados em organizações inovadoras destacam-se: busca de oportunidades e iniciativa, estabelecimento de metas, planejamento e monitoramento sistemáticos, persuasão e redes de contatos, independência e autoconfiança. Como perspectivas futuras de investigação, têm-se um vasto campo para explorar em as singularidades da manifestação do empreendedorismo interno nas organizações contemporâneas e em perspectiva comparada, especialmente naquelas inseridas no contexto da inovação.

\section{Palavras-Chave}

Empreendedorismo Corporativo, Intraempreendedorismo, Inovação.

\section{EVIDENCES OF INDOOR ENTREPRENEURSHIP IN ORGANIZATIONS IN THE INNOVATION CONTEXT}

\begin{abstract}
This study is a theoretical essay resulting from a research about the construction of knowledge in entrepreneurism in Brazil. It aims at identifying and discussing the evidences of the internal entrepreneurism, having as basis two empirical elements, the "Intra-entrepreneurism" and "Corporative Entrepreneurism" in organizations in the innovation context. In methodological terms, the data sources were essentially secondary, having as basis the main technical and scientific production concerning this theme in the events organized by the Associação Nacional de Pós Graduação e Pesquisa em Administração (ANPAD). The principles of meta-analysis and the content analysis technique were used, and they permitted to observe the differences between the Intra-entrepreneurism and the Corporative Entrepreneurism in organizational and behavioral terms. Among the main results, it is observed, as reflections needed in the field, the necessity to clarify the elements that distinguish corporative entrepreneurs from the internalentrepreneurs in the organizations, as well as understand the element that stimulate behaviors turned to the internal entrepreneurism. Among the more evidenced behaviors turned to the innovation in organizations of technological basis the ones which stand out are: search for opportunities and initiatives, establishment of targets, systematic planning and monitoring, persuasion and network, independence and self-confidence. As future perspectives of investigation, there is a vast field to explore in the singularities of the manifestation in contemporary organizations of internal entrepreneurism in Brazil in a comparative perspective, especially in the ones inserted in the innovation context.
\end{abstract}

\section{Keywords :}

Corporate Entrepreneurship, Intra Entrepreneurship, Innovation. 


\section{Introdução}

Os estudos realizados nos últimos anos sobre o tema empreendedorismo interno trazem evidências de que o conceito não está bem disseminado e consolidado entre pesquisadores. Porém, percebe-se que há uma conjuntura socioeconômica em que os comportamentos empreendedores dos empresários e donos de negócios não são suficientes para o crescimento e desenvolvimento das organizações que possuem seu foco na inovação tanto como estratégia quanto delineador de sua estrutura organizacional.

Esse argumento ganha projeção na medida em que a produção científica tem chamado a atenção para o fenômeno do "empreendedor interno" que se apresenta empiricamente nas organizações sob os rótulos de intra-empreendedor e empreendedor corporativo. Mas, são esses rótulos fidedignos de diferenciação? Ou são "etiquetas" de uma mesma coisa?

Entendemos como "coisa" aquele objeto que segundo Durkheim (2002) é possível de ser observável, contemplando inferências sobre ele que não emanam de "achismos", causadores de distorções da realidade social, mas sim de evidências empíricas de estudos rigorosamente elaborados. Desta forma, acreditamos que a distinção entre intra-empreendedorismo e empreendedorismo corporativo não se limita à questão semântica, ou seja, ao "rótulo".

Esse argumento tem sido evidenciado nas pesquisas nacionais e internacionais sobre este tema, porém poucos pesquisadores em seus trabalhos se preocuparam em apresentar evidências que distinguem os dois termos. Um estudo que demonstrou tal preocupação foi elaborado com a participação de dois dos autores presentes neste artigo, que apresentaram elementos estrutural e comportamentais de diferenciação entre o intra-empreendedor e o empreendedor corporativo. Segundo Emmendoerfer et al. (2008), em termos estrutural, a posição ou o cargo que o individuo ocupa na hierarquia da organização tende a normatizar e condicionar o horizonte de atuação tanto do intra-empreendedor (que é mais focalizado no ambiente interno da organização), quanto do empreendedor corporativo (que é voltado mais para o ambiente externo). Em termos comportamentais, "correr riscos calculados" revelou ser algo mais evidente no empreendedor corporativo, e o "comprometimento" foi verificado como sendo o comportamento mais freqüente nos intra-empreendedores, conforme Emmendoerfer et al. (2008).

Neste sentido, é possível delimitar quem é o intra-empreendedor e o empreendedor corporativo através do cargo e do comportamento de cada um na organização onde atua. Assim a partir do trabalho organizado pelos autores supracitados, consegue-se identificar em estudos da área especializada da administração, evidências de atuação de cada tipo de empreendedor interno. Mas, será isso factível em organizações no contexto da inovação?

Eis o problema de pesquisa deste trabalho que irá nortear o objetivo do nosso trabalho que é identificar e discutir evidências da prática do empreendedorismo interno, tomando como base os elementos empíricos, "Intra-empreendedorismo" e "Empreendedorismo Corporativo" em organizações no contexto da inovação.

Vale esclarecer que a inovação é entendida neste trabalho, segundo Emmendoerfer (2002), como a introdução de algum elemento que modifica algo de forma nova, que pode ser fruto de um processo criativo, fazendo com que este "novo produto" torne-se diferente de modo evolutivo, a partir do conhecimento aplicado, seja ele científico ou empírico. A unidade de análise é o empreendedor interno. Porém, será utilizada a organização como seção importante para situar o empreendedor interno contextualmente, bem como auxiliar no entendimento de suas características e de seus espaços ou configurações organizacionais em que ele está mais evidente. Para tanto, será apresentada uma breve revisão teórica que permite retratar a construção e produção do conhecimento sobre empreendedorismo interno, com destaque para a distinção entre intra-empreendedor e empreendedor corporativo nas organizações.

\section{Construção e Produção do Conhecimento Sobre Empreendedorismo Interno}

No Brasil, o levantamento, análise e discussão de periódicos e anais de eventos técnico-científicos tem se apresentado num delineamento metodológico produtivo para que se obtenha conhecimento nas áreas que compõem as ciências administrativas como apontam os trabalhos de Machado-da-Silva, Cunha e Amboni (1990) e Bertero, Caldas e Wood (1998). Somado a isso, considerando a experiência adquirida com esta estratégia de pesquisa por Emmendoerfer, Valadares e Balbi (2008) no campo do empreendedorismo 
interno, pressupõe-se que ela seja adequada também para conhecer com mais profundidade o objeto desta pesquisa, em termos organizacionais e comportamentais no contexto da inovação.

Essa estratégia de pesquisa tem sido operacionalizada por meio da meta-análise (ALBERNETHY e FRANKE, 1996; HUNT, 1997; EPSTEIN, 1998) que é caracterizada como sendo o "estudo dos estudos". Ela possibilitou no trabalho de Emmendoerfer, Valadares e Balbi (2008) mapear o tema empreendedorismo interno em trabalhos publicados em eventos científicos no Brasil. Este trabalho identificou baixa produção científica sobre este tema, porém com sinais de crescimento da produção nos últimos anos. Somente onze trabalhos foram identificados sobre o tema, sendo cinco trabalhos acerca de intra-empreendedorismo e, seis, sobre empreendedorismo corporativo.

Esses autores observaram que na medida em que a organização cresce e detém um tamanho considerado de médio ou grande porte em seu mercado de atuação, a discussão e a prática quando percebidas com o termo "empreendedorismo interno" começam a ser segmentada em dois tipos ou formas de manifestação no interior das organizações: intra-empreendedorismo e empreendedorismo corporativo. Tal evidência exige atenção dos estudiosos no campo em distingui-los adequadamente em suas pesquisas, para se evitar possíveis equívocos conceituais. Para tanto, neste trabalho foi utilizada o arcabouço levantado por Emmendoerfer, Valadares e Balbi (2008) e avança na construção do conhecimento no campo fazendo uso da técnica de análise de conteúdo (BARDIN, 2004) que permitiu realizar o emparelhamento de dados tomando como base os assuntos "intra-empreendedorismo" e "empreendedorismo corporativo" identificados na bibliografia presente neste trabalho. O emparelhamento constou da seleção lexical de duas categorias relevantes para atingir o objetivo desta pesquisa sobre empreendedorismo interno: (1) características comportamentais; e (2) características organizacionais. Essas duas categorias possibilitaram compor, enquanto requisitos parciais, os principais "achados" dos pesquisadores deste trabalho sobre o objeto em estudo, sendo elas descritas e discutidas nas próximas seções.

\subsection{Os Tipos de Empreendedorismo Interno}

Existem autores que não demonstram interesse ou preocupação em diferenciar os dois tipos de empreendedorismo interno discutido neste trabalho. Para eles não é necessário preocupar-se em diferenciá-los constitutivamante, com profundidade científica. Um desses autores é o professor José Dornelas. Este, admite que o empreendedorismo interno possa ser definido como a ação de empreendedores dentro das organizações, no exercício da criatividade em favor de inovações futuras tomando sobre si um comprometimento com as ações organizacionais, a ponto de sentir-se "proprietário" de sua área de trabalho (DORNELAS, 2003). Deste modo o empreendedor interno possui autonomia para tomar decisões em sua unidade estratégica de negócio (UEN) de forma que essas decisões possam ser aceitas pela alta administração (HASHIMOTO, 2006).

Porém outros autores como Emmendoerfer, Valadares e Balbi (2008), Hashimoto (2006) estão em busca de diferenças nestes dois tipos de empreendedorismo interno para poder discutir a ação destes agentes dentro das empresas de inovação. A diferença fundamental que estes dois tipos de empreendedorismo interno possuem reside no horizonte de atuação de cada um desses sujeitos em virtude da posição em que eles ocupam na organização. Segundo Emmendoerfer, Valadares e Balbi (2008, p.2), "enquanto o intraempreendedor tem como horizonte a inovação nos produtos, processos e procedimentos no interior da própria organização, o empreendedor corporativo tem o seu horizonte centrado no mercado, buscando desenvolver novas estratégias e negócios para a própria organização". Neste ínterim, observa-se que o intra-empreendedor inova para alcançar benefícios e vantagens para a organização visando à criação ou melhoramento de processos, produtos e serviços para a organização, ou seja, tem seu foco no ambiente interno da indústria. Todavia, o empreendedor corporativo possui uma visão voltada para o mercado, ou seja, está em busca de desenvolver estratégias para que a organização torne-se mais competitiva. Contudo, apesar de tais diferenças tanto os primeiros quanto os segundos tem uma influência no processo de inovar da organização cada um atendo-se ao próprio ambiente de atuação (VALADARES e EMMENDOERFER, 2009).

Emmendoerfer, Valadares e Balbi (2008, p. 2) evidenciaram que características do comportamento empreendedor (UNCTAD, 2008) como busca de oportunidades e iniciativa, busca de informações e iniciativa, e independência e autoconfiança foram predominantes durante a análise das publicações demonstrando serem características comuns tanto em intra-empreendedores quanto em empreendedores corporativos. 
Entretanto, resgata-se o argumento da diferenciação entre intra-empreendedores e empreendedores corporativos, apresentado no início deste trabalho, que será legitimado com a exposição de mais algumas características que distinguem esses comportamentos nas organizações.

\subsection{Intraempreendedor (ie)}

O intra-empreendedor é caracterizado pela busca de seu crescimento pessoal/profissional, através do desenvolvimento de novos produtos, processos e procedimentos de trabalho (HISRICH; PETERS, 2004). Para que este indivíduo consiga se realizar no ambiente das organizações, ele deve ser incitado a desenvolver competências empreendedoras que o tornam um empreendedor inserido na estrutura da organização. Estas competências estão relacionadas ao desejo de auto-realização; se o indivíduo é criador ou inventor que planeja transformar idéias em oportunidades dentro da organização; se é um profissional que quando recebe a devida liberdade, incentivo e recursos da organização onde trabalha, procura estar dedicando-se arduamente em converter idéias em produtos ou processos (PINCHOT III, 1989). Percebe-se que se o intra-empreendedor obtiver espaço para que suas idéias sejam realizadas e sua criatividade seja levada em consideração, ele tornará um agente de mudanças em seu espaço de trabalho, pois, sua busca constante por crescimento profissional/carreira culminará em ótimos resultados para a empresa, gerando uma maior satisfação para a empresa e sociedade.

É relevante dizer que o intra-empreendedor vivencia emoções, riscos, relativo grau de dependência na tomada de decisões e gratificações de uma idéia que se tornou realidade a partir de uma visão voltada a esfera organizacional (FILION, 2004). Assim, o intra-empreendedor é um dos agentes que conseguem impulsionar uma importante variável que influi no crescimento/expansão de uma organização, a inovação, pois, possui um "espírito intrapreneur" fazendo com que ele tenha um comportamento diferenciado e vantajoso para a organização (PINCHOT III, 1989) no contexto da inovação. Normalmente o intraempreendedor pode ser qualquer indivíduo organizacional não importando sua posição hierárquica, dado que sua visão está voltada para a inovação de produtos, processos e serviços internos. Neste ínterim quanto mais é aprimorada a capacidade de formar intra-empreendedores na organização, pressupõe-se que esta se torna mais competitiva frente aos concorrentes. Portanto, considera-se que o intraempreendedor é um agente estratégico para a organização onde atua no que tange a aceleração de inovações dentro das organizações. Tal aceleração tende a ser obtida, uma vez que as bases do comportamento empreendedor passam a estar intimamente ligadas com a capacidade inovadora do indivíduo. Neste sentido, infere-se que o intra-empreendedorismo e a inovação, têm uma íntima ligação através da ação das características do comportamento empreendedor voltadas a criação e a melhoria de processos e produtos nas organizações. Portanto para que a organização tenha empreendedores internos, esta deve ater-se também ao desenvolvimento de uma estrutura em que a inovação será uma condição para se alcançar os objetivos organizacionais.

Diante desta situação percebe-se que o desenvolvimento de intra-empreendedores se configura como um novo benefício para que as organizações se perpetuem, assegurem ou aumentem sua participação de mercado. Neste sentido, desenvolver empreendedores internos é uma saída para que as organizações sobrevivam em meio a incertezas e para que possam desenvolver seus negócios, principalmente em momentos de crise, frente àquelas que não têm como uma de suas premissas gerarem intraempreendedores ou empreendedores corporativos (GUIMARÃES e MACHADO-DA-SILVA, 2006; VALADARES e EMMENDOERFER, 2009; IRELAND, COVIN E KURATKO 2009; PHAN, 2009).

Desenvolver intra-empreendedores gera benefícios para organização ao estimular o senso de responsabilidade nos indivíduos, fazendo com que eles assumam o bônus e ônus pela criação de suas inovações no processo de trabalho e em seus produtos. Assim, o intra-empreendedor tende ir à busca dos objetivos da organização para o alcance de suas próprias metas. Portanto, o intraempreendedorismo configura-se num processo de expansão do domínio da organização em competência (STONER e FREEMAN, 1994), em que o perfil dos intra-empreendedores se assemelha ao de agente de mudanças a fim de melhorar os produtos e processos internos da organização em que atuam (SANTOS e LEZANA, 2001).

\subsection{Empreendedor Corporativo (ec)}

Outra denominação que se dá para o indivíduo que possui um comportamento empreendedor dentro das organizações é o empreendedor corporativo. Este sujeito, normalmente, está envolvido com 
lançamentos de novos produtos, decisões sobre fusões e aquisições, novos negócios para a organização, reestruturação organizacional, busca de novas parcerias ou revisão das parcerias existentes e, por isso, detém a autonomia para mudar a estratégia de sua unidade estratégica de negócio (HASHIMOTO, 2006).

Normalmente, o empreendedor corporativo faz parte de organizações que são caracterizadas como holdings ou corporações no âmbito regional, nacional e internacional, atuando como gestor de UEN unidades estratégicas de negócios, faz parte do alto escalão das organizações, isto é, trabalham na alta administração podendo ser representantes dos acionistas em conselhos administrativos, consultores e especialistas da área de gestão empresarial, planejamento estratégico e desenvolvimento de novos negócios que enfrentam a decisão de estabelecer diferença ou não nos seus negócios (SEIFFERT, 2005; CHIEH e ANDREASSI, 2007; EMMENDOERFER, VALADARES e BALBI, 2008). Neste ínterim o Empreendedor Corporativo objetiva oportunidades presentes no ambiente mercadológico para que sejam desenvolvidas inovações no que tange o estabelecimento de novos negócios, novo posicionamento no mercado fazendo assim com que ele possua uma grande propensão a correr riscos calculados. Dado a autonomia para tomar decisões, o empreendedor corporativo incorre no risco de não conseguir gerar resultados na sua UEN, podendo gerar um prejuízo grande para a empresa e assim podendo perder seu próprio emprego. Assim o empreendedor incorre em riscos empresariais e profissionais.

Sendo assim infere-se que a atuação do empreendedor interno é de suma importância para o desenvolvimento de inovações na organização independentemente do setor que ela está inserida. Para tanto as organizações que desenvolvem empreendedores internos devem levar em conta barreiras que impeçam o desenvolvimento do comportamento empreendedor, dado que estas podem ser fatores limitantes ao desenvolvimento de tais características. As barreiras mais comuns são: rigidez dos processos de aprovação e decisão; gerências centralizadoras; alta formalização do processo de trabalho; falta de espírito de equipe; delimitações impostas pelas descrições de cargo; obediência irrestrita às normas e padrões internos; pouca ou nenhuma tolerância a erros e fracasso; e falta de orçamento para empreendimentos de risco (EMMENDOERFER, VALADARES, BALBI, 2008).

Para minimizar essas barreiras organizacionais é fundamental compreender as características do espaço organizacional em que se cultiva (EMMENDOERFER, 2000; 2008; EMMENDOERFER; COLAÇO e PEREIRA, 2006), em menor ou maior grau, os comportamentos do empreendedorismo interno

Com base nas diferenças entre apresentadas entre intra-empreendedores e empreendedores corporativos nas organizações, foi possível configurar o seguinte quadro comparativo.

Quadro 1 - Diferenças entre Empreendedorismo Corporativo e Intra-empreendedorismo

\begin{tabular}{|l|l|}
\hline \multicolumn{1}{|c|}{ Empreendedorismo Corporativo } & \multicolumn{1}{c|}{ Intra-empreendedorismo } \\
\hline Iniciativas surgem da alta administração & $\begin{array}{l}\text { Iniciativas surgem do funcionário de nível intermediário ou } \\
\text { operacional }\end{array}$ \\
\hline $\begin{array}{l}\text { O horizonte da inovação está direcionada a gestão e } \\
\text { criação de novos negócios. }\end{array}$ & $\begin{array}{l}\text { O horizonte da inovação está direcionada a produtos, processos e } \\
\text { procedimentos internos. }\end{array}$ \\
\hline $\begin{array}{l}\text { Projetos relacionados com o negócio (o interesse está na } \\
\text { relações interorganizacionais) }\end{array}$ & $\begin{array}{l}\text { Projetos abrangem qualquer área da organização (o interesse } \\
\text { está nas relações intraorganizacional) }\end{array}$ \\
\hline Foca a estratégia corporativa (ambiente externo) & $\begin{array}{l}\text { Foca o comportamento do colaborador e a cultura corporativa } \\
\text { (ambiente interno) }\end{array}$ \\
\hline Projetos são liderados pela alta administração & Projetos são liderados por membros de qualquer nível hierárquico \\
\hline Riscos relacionados com o mercado & Riscos primordialmente internos à organização \\
\hline Projetos de alta complexidade & Projetos de baixa complexidade \\
\hline
\end{tabular}

Fonte: Elaboração Própria

Desta forma, conhecendo a natureza do empreendedorismo interno e suas diferenças, evidenciadas entre os empreendedores corporativos e intra-empreendedores nesta seção, é possível discuti-los no espaço organizacional no contexto da inovação a seguir. 


\section{Os Tipos de Organizações Propulsoras do Empreendedorismo Interno}

No contexto da inovação, a literatura especializada na área de administração tem indicado evidências de alguns tipos ou formatos de organizações que têm se apresentado como espaços estimuladores para o desenvolvimento do empreendedorismo interno. Vale destacar que o nosso interesse reside na organização inovadora, porém acreditamos ser pertinente distingui-las das organizações empreendedoras e criativas, como forma de delimitar a nossa discussão e evitar imprecisões teóricas e empíricas.

\subsection{Organização Empreendedora (Oe) E Organização Criativa (Oc)}

A organização empreendedora possui, conforme Mintzberg (1995), uma estrutura simples com poucos níveis hierárquicos, normalmente conduzidos por supervisão direta. Tal meio de coordenação é executado comumente pelos proprietários da organização, inclusive (naquelas) de base tecnológica. Há poucas evidências de treinamento e especialização quando não existe suporte de outras organizações ou instituições como as de educação universitária ou tecnológica, incubadoras e agências de desenvolvimento local ou regional. Também há pouca formalização e especialização do processo de trabalho, o que abre oportunidades para o desenvolvimento do empreendedorismo interno. Porém, a pouca perícia dos proprietários em relação à gestão no que concerne ao planejamento e controle pode desestimular a permanência de potenciais empreendedores internos.

As organizações empreendedoras são caracteristicamente jovens e pequenas, situadas num ambiente dinâmico em que a presença de empreendedores corporativos é normalmente ausente, configurando-se num espaço de desenvolvimento inicial de intra-empreenderes desde que a organização caminhe para processos de formalização e descentralização do processo de comunicação e tomada de decisão, como será visto na organização inovadora. Contudo, antes de introduzi-la, é pertinente apresentar as organizações criativas.

As atividades econômicas relacionadas com a cultura aparecem atualmente com a denominação de indústrias criativas. Nestas fazem parte as organizações criativas. Por um lado, mesmo ganhando atenção inicial em países como Inglaterra e Austrália, em seguida, no Brasil (WOOD Jr. et al., 2009), os estudos das indústrias criativas demandam novas perspectivas de análise como o debate do empreendedorismo interno para o entendimento de sua gestão.

Nota-se que a cultura vem sendo abordada sob uma lógica econômico-comercial em que estão relacionados consumidores, atividades industriais e organizações públicas e privadas. Atualmente este mercado está sendo denominado como indústrias criativas, que inclui organizações com atividades econômicas como: antiguidades, arquitetura, arte, artesanato, artes performáticas, design, design de moda, editoras, filme e vídeo, jogos de computador, música, publicidade, serviços de software e computadores, TV e rádio (OAKLEY, 2004; URICCHIO, 2004).

Percebe-se que as organizações criativas estão inseridas em setores econômicos que antes não estavam relacionados com o mercado cultural, mas que tem como base fundamental a criatividade em suas operações. Este aspecto revela a importância do empreendedorismo interno que dependendo do tamanho da organização, seja numa estrutura única ou articulada em rede, permite desenvolver tanto o intra-empreendedorismo quanto o empreendedorismo corporativo. Porém, tal debate é ainda incipiente na literatura especializada em administração em virtude da discussão deste tipo de organização ser recente.

Assim, as organizações criativas podem ser empreendedoras, porém para se manterem no mercado tendem a incorporarem características burocráticas (WEBER, 2004) e práticas de inovação. Diante disso, iremos compreender a natureza da organização inovadora e sua interlocução com o empreendedorismo interno, objeto deste trabalho.

\subsection{Organização Inovadora (Oi)}

Uma inovação é uma idéia nova que pode ser a recombinação de idéias velhas. É um esquema que desafia a ordem presente ou a única abordagem vista como nova pelas pessoas envolvidas (VAN DE VEN, 1986). Neste sentido, entende-se que o empreendedor interno legitima a ascensão de inovações dentro das organizações, pois, a implantação de uma inovação passa por uma propensão de indivíduos qualificados que podem proliferar as idéias inovadoras na organização. Essa capacidade de fazer com que os insights inovadores percorram a organização faz desse indivíduo um diferencial competitivo, 
especificamente na identificação de oportunidades de melhoria de processos e produtos. Entende-se que o processo de gerar novas idéias tem a criatividade, como habilidade importante para que os empreendedores consigam introduzir suas idéias e aperfeiçoamentos na organização.

Para uma organização ser inovadora, Cozzi e Arruda (2004) observaram que ela precisa ter um sistema de gestão interno bastante flexível, onde há uma intensa troca entre os sistemas formais e informais de comunicação, fazendo com que haja uma intensa troca de informações entre a organização e seu ambiente externo. Desta maneira as pessoas se tornam um fator crucial para vantagem competitiva das organizações, pois, quem conduz o desempenho da organização, são as pessoas e não a estrutura e as regras. No entanto para que este sistema flexível seja eficaz a forma de gerenciar pessoas deve ser dinâmica e orgânica, pois, a necessidade de manter iniciativa individual é latente na empresa. Diante disso, o foco da administração da organização é o alcance dos objetivos em detrimento da busca pela eficiência (EMMENDOERFER, VALADARES E BALBI, 2008).

Uma característica peculiar da organização inovadora é a estrutura organizacional invertida, apresentando poucos níveis hierárquicos em suas unidades de negócios. Este tipo de estrutura cria condições para que as tomadas de decisões, concernentes a inovação e identificação de novas oportunidades, sejam feitas por pessoas e grupos de negócio que estão em constante interação junto aos clientes e o mercado. Isso tende a aumentar a eficácia organizacional e conseqüentemente sua competitividade frente aos outros concorrentes que adotam estrutura vertical e matricial, pois, os indivíduos trabalham em busca de um objetivo comum e atuam entrelaçados num ambiente de cooperação e interdependência. Este fato faz com que tais indivíduos não deixem de lado os seus desejos e sonhos individuais, porque as escolhas e os sonhos individuais são colocados num plano coletivo de construção de um escopo maior.

Quando há uma preocupação dos gestores em gerar o fator inovação nas organizações, por meio de novos processos como o supracitado, a ação mútua exercida por parte da administração da organização para desenvolver o comportamento autônomo dos funcionários-empreendedores é outro fator que aumenta a eficácia da organização, pois, esta atitude autônoma dos colaboradores constitui um fator preponderante para que as organizações se tornem mais estratégicas no intuito de mobilizar recursos corporativos para novas oportunidades, identificadas interna ou externamente à organização.

A partir dessa pressuposição é importante salientar que o empreendedorismo pode atuar como estratégia corporativa das organizações em resposta às pressões ambientais competitivas, por meio de inovações ou práticas miméticas. O empreendedor interno através de seu comportamento autônomo pode atuar nas estratégias de mudanças, bem como no planejamento condicionando equilíbrio para criação de novas idéias, inclusive atuando no melhoramento dos processos já existentes (GUIMARÃES E MACHADODA-SILVA, 2006).

Uma forma que Pessoa e Gonsalves (2004) fizeram para enxergar uma maneira de inovar em uma instituição de ensino superior federal foi propor uma nova metodologia de ensino da disciplina Administração empreendedora fundamentada numa abordagem livre, flexível que condicionassem nos alunos o senso de auto didática para que criassem seu próprio método de aplicar a disciplina. Em relação ao método inovador de ministrar a disciplina, as autoras revelam que o objetivo é desenvolver nos alunos o espírito empregado-empreendedor através da aprendizagem dos comportamentos empreendedores. Entretanto, para que estes indivíduos possam atuar de maneira autônoma, a organização em si deve desenvolver um ambiente propício para criar determinadas características em seus colaboradores (EMMENDOERFER, VALADARES E BALBI, 2008).

É de suma importância que os empreendedores internos entendam o valor de seus comportamentos para que possam dedicar sua criatividade e capacidade de inovar para a organização. Percebe-se que estes têm se tornado uma estratégia de valor relevante para que organizações enfrentem situações duvidosas e contraditórias. Cardoso e Filho (2003) inferem que o empreendedorismo corporativo é uma questão de sobrevivência para organizações submetidas a pressões constantes, nos setores dinâmicos da economia.

É importante salientar que a inovação independe do setor onde a organização está sendo desenvolvida. Pesquisadores têm encontrado evidências do desenvolvimento de empreendedores internos em diversos ramos da economia e em diversos tipos de organizações fazendo com que as organizações se tornem mais orgânicas e para que possam adaptar à nova realidade da economia mundial. Assim, tais evidências mostram o quanto à inovação está incutida na realidade das organizações, pois, até em ramos econômicos onde a pouco tempo não se conseguia enxergar a inovação, estudos recentes mostram que os gestores 
estão mudando sua forma de pensar e agir na estrutura organizacional frente à inovação (ZIMMER e HOELTGEBAUM, 2004; SEQUEIRA, 2005; BORINI, OLIVEIRA JÚNIOR E GUEVARA, 2005; MALLMANN, BORBA E RUPPENTHAL, 2005; CHIEH E ANDREASSI. 2007; CÂMPELO e ALMEIDA, 2007).

Referente a tal especulação Zimmer e Hoeltgebaum (2004) fizeram um estudo sobre a empregabilidade dos funcionários de uma estatal identificando que é possível implantar o empreendedorismo interno em uma organização pública. Essas autoras identificaram habilidades intra-empreendedoras nos funcionários de uma estatal que aderiram a um programa de dispensa incentivada. Este programa contribuiu para despertar o espírito empreendedor e desenvolver a empregabilidade nos indivíduos porque dava liberdade para todos escolherem se desejam permanecer na organização para lidar com as mudanças e colher os benefícios gerados ou buscar novas oportunidades de trabalho no mercado com recursos financeiros para começar ou investir em novos negócios. Para as pesquisadoras, é duvidosa a relação entre estabilidade de emprego e esforço para se fazer um trabalho de qualidade. Por isso, as autoras mostraram para os empregados que somente por meio de estímulos de comportamentos empreendedores (especialmente, aqueles associados ao risco e a incerteza) poderiam desenvolver em sua massa crítica, habilidades encontradas em organizações privadas para que se tornassem mais competitivos (ZIMMER e HOELTGEBAUM, 2004).

De uma forma parecida Sequeira (2005) fez um estudo em uma Organização não Governamental (ONG) no intuito de demonstrar que nesta organização os empregados/empreendedores podem inovar utilizando práticas de gestão utilizada no empreendedorismo interno. Com o objetivo de identificar à ocorrência efetiva de ações que possam ser associadas ao intra-empreendedorismos, a autora concluiu que, em organizações do terceiro setor, podem ser utilizadas práticas correspondentes ao empreendedorismo interno demonstrando a que a inovação na forma de gerir a ONG condicionaria a legitimação e sustentabilidade da organização (EMMENDOERFER, VALADARES e BALBI, 2008).

Portanto entende-se que a inovação está presente nas organizações que buscam uma nova forma de gerenciar suas pessoas através do desenvolvimento do comportamento empreendedor. Neste sentido, Garcez e Sbragia (2006) inferem que o comportamento empreendedor dos sujeitos empregados nas organizações é um processo constituído de inúmeras situações que tem por meta explorar os comportamentos e as atitudes empreendedoras através do estímulo da cultura empreendedora, o aprendizado organizacional e o gerenciamento da inovação no ambiente interno da organização (EMMENDOERFER, 2008; BALBI e VALADARES, 2008). Tais características são incentivadas com o intuito de alcançar o desenvolvimento de novas combinações de insumos, criação e administração de novos negócios dentro da organização. O empreendedor interno tem papel importante nesse processo de criação e administração de novos negócios corporativos, pois, ele é um dos determinantes para as estratégias de crescimento e entrada em novos negócios. Segundo os autores o empreendedor corporativo pode ser desenvolvido em vários níveis da hierarquia organizacional, porém sua amplitude de atuação é limitada de acordo com a sua função e autonomia atribuída pela chefia.

\section{Considerações Finais}

Este trabalho demonstrou que na prática da teorização sobre empreendedorismo interno é possível encontrar simplificações ou generalizações não somente no uso desse termo, mas também da estrutura organizacional em que os indivíduos como empregados estão inseridos. Em alguns casos, há sinais de um aparente desconhecimento do desenho organizacional e o quanto ele é importante para o desenvolvimento de comportamentos direcionados ao empreendedorismo interno. Um aspecto mais alarmante neste sentido é a exposição deste tema considerando os indivíduos como pessoas "soltas no espaço" ou "independentes" das condições institucionais existentes na organização em que atua. Aliás, foi verificado que o debate sobre estrutura organizacional em estudos sobre empreendedorismo revela sinais de desarticulação ou necessidade de aproximações teóricas para se entender melhor a sua prática. Diante disso, uma das contribuições deste trabalho foi esclarecer a forma em que o empreendedor interno se apresenta e que pode ser evidenciado nas organizações, enquanto agente propulsor de crescimento e desenvolvimento organizacional.

Somado a isso, verificou-se a importância de se observar a existência de distinções de "coisas" ou comportamentos empreendedores, aparentemente semelhantes em essência, mas distintos empiricamente nas organizações, que, aliás, como foi observado na seção anterior, também se distinguem entre si no contexto da inovação. 
Na prática, há generalizações entre os tipos de organização (empreendedora e criativa em relação à organização inovadora) expostos neste trabalho porque é comum existir nessas organizações, um mix de práticas empreendedoras, criativas e, em menor grau, inovadoras. Por um lado, isso pode ser considerado uma limitação deste trabalho. Por outro, esta evidência não mostra necessariamente que os tipos organizacionais apresentados neste trabalho, são simplesmente estágios preliminares ou uma postura de rompimento com o modelo burocrático organizacional (DELLAGNELLO, 2000), mas sim configurações organizacionais, híbridas com certos delineadores da estrutura organizacional voltada ao contexto da inovação. Neste sentido, há um sistema de coordenação que tende a predominar na estrutura das organizações apresentadas para viabilizar o desenvolvimento do empreendedorismo interno que é o ajustamento mútuo entre os funcionários.

Vale lembrar que o ajuste mútuo é um processo de comunicação informal e de confiança mútua estabelecidos pelos indivíduos que ocupam normalmente posições hierarquicamente semelhantes (MINTZBERG, 1995; EMMENDOERFER, 2004). Os indivíduos "se adaptam uns aos outros de maneira informal por processos de comunicação interpessoal, compartilhando informações relacionadas ao trabalho" (THOMPSON, 1967, p.62). De acordo com Mintzberg (1995), o ajuste mútuo é caracterizado pela descentralização na dimensão horizontal em organizações inovadora e centralizado no topo em organizações empreendedoras. O modo como um trabalho deve ser realizado e quem deverá realizá-lo é definido pelos próprios atores na organização inovadora, dentro de um conjunto de limitações prescritas aos atores e as unidades pelos níveis superiores da organização. O ajuste mútuo é exercido quando as unidades ou locais de trabalho dos atores estão "fisicamente muito próximas, permitindo o compartilhamento de facilidades comuns, o que encoraja a ter freqüentes contatos entre si" (MINTZBERG, 1995, p.54) e quando as unidades são pequenas e informais é estimulado o trabalho cooperativo, quando o intuito é desenvolver o empreendedorismo interno e não somente o próprio empreendedor como acontece nos pequenos negócios, inclusive de base tecnológica.

A coordenação pelo ajuste mútuo possui vários instrumentos de interligação comumente utilizados por empreendedores corporativos como contato direto e indireto (e-mail, pager e telefone) entre os atores de mesma posição hierárquica, reuniões presenciais ou virtuais com os membros da equipe que atua como força-tarefa e em comissões permanentes na organização. Além desses instrumentos de interligação, devido à restrita amplitude do controle, os empreendedores internos atuam como negociadores que estimulam a integração entre equipes ou áreas distintas, bem como peritos com poder de decisão no desenvolvimento de suas atividades e projetos na organização.

A organização controlada principalmente pelo ajuste mútuo é comumente muito simples (como a empreendedora), ou muito complexa (como a inovadora), sendo caracteristicamente jovem (ou induzida a tal postura identidária), possuindo um sistema técnico muito sofisticado, às vezes, automatizado na área administrativa e não regulado na parte operacional (EMMENDOERFER, 2004). As relações de poder são manifestadas pelo controle da perícia dos atores organizacionais, normalmente, representados pelo pessoal de assessoria de apoio que seguem muito a moda ou as tendências do mercado (MINTZBERG, 1995). O exercício do ajuste mútuo como mecanismo-chave de coordenação é reflexo de uma ambiente dinâmico e complexo. O controle é distribuído irregularmente por toda organização, conforme a perícia e as necessidades tanto das organizações (MINTZBERG e QUINN, 2001) quanto de seus empreendedores internos.

Com base nessas considerações, percebe-se enquanto reflexões necessárias no campo, a necessidade de mais esforço para a clarificação dos elementos que distinguem os empreendedores corporativos dos intra-empreendedores, bem como de suas organizações, no contexto da inovação.

Neste sentido, discutir a relação indivíduo e organização no campo do empreendedorismo interno revela-se um desafio para os pesquisadores que buscam compreender este fenômeno importante para a gestão tecnológica. Observou-se que são dois conceitos diferentes, mas o mal está em confundi-los e não necessariamente em ter um dos dois em detrimento do outro. As aplicações no meio acadêmico são profundamente relevantes, pois há muita confusão no uso dos termos de forma apropriada. Isso pode ser evidenciado pelo levantamento da literatura de uma forma qualitativa. Outra contribuição deste artigo para o meio acadêmico está justamente na formação de uma base epistemológica sobre o conceito. Já, para a prática gerencial e corporativa, o importante é deixar claro que, com as diferenças expostas, os dirigentes e gestores de pessoas podem definir estratégias de desenvolvimento de uma cultura intra-empreendedora ou de novos negócios corporativos, dependendo do que se pretende atingir na sua estratégia. Contudo, as limitações deste trabalho reside no fato desta pesquisa se restringir ao levantamento da literatura em 
termos bibliográficos, que pode ser incrementada ou revisitada com futuros estudos de campo do tipo survey, buscando captar a interpretação que cada gestor faz dos comportamentos empreendedores em suas organizações.

Vale destacar que os comportamentos voltados ao empreendedorismo interno mais evidenciados neste trabalho, identificados nas organizações foi: busca de oportunidades e iniciativa, estabelecimento de metas, planejamento e monitoramento sistemáticos, persuasão e redes de contatos, independência e autoconfiança. Como perspectivas futuras de investigação, têm-se um vasto campo para explorar em termos teóricos e empíricos as singularidades da manifestação nas organizações contemporâneas do empreendedorismo interno no Brasil e em perspectiva comparada, especialmente, em organizações inseridas no contexto da inovação.

Infere-se que a inovação está disponível para todas as organizações, porém gerenciável para algumas (como aqueles tipos apresentados na seção anterior) que têm demonstrado que é possível agregar valor estruturalmente dos benefícios incorridos por ela em sua estrutura e ambiente mercadológico, não importando necessariamente o setor econômico que ela atua. Apesar das barreiras encontradas para que realmente a inovação seja efetiva nas organizações, evidenciou-se neste artigo um interesse comum de disseminar o espírito empreendedor em prol de vantagens competitivas por meio da inovação. Portanto, não será esse um dos desafios da gestão tecnológica nos próximos anos? Mais do que estimular o empreendedorismo e a geração de trabalho e renda, este trabalho demonstrou que é preciso, primeiramente conhecer com profundidade o empreendedorismo interno, para em seguida saber desenvolve-lo e gerenciá-lo a fim de tornar as organizações efetivamente inovadoras e, não somente, empreendedoras e criativas.

\section{Referências}

ALBERNETHY, A. M.; FRANKE, G. R. "The information content of advertising: a meta-analysis". Journal of Advertising, v. 25, n. 2. Minneapolis: American Academy of Advertising, 1996, p. 1-17.

BALBI, R. V.; VALADARES, J. L. Estratégia e planejamento. bases da cultura empreendedora. um trabalho teórico In: Simpósio de Gestão da Inovação Tecnológica, 25. Anais... Brasília (DF). SIMPÓSIO/ANPAD. 2008. CD.

BARDIN, L. Análise de conteúdo. 3. ed. Lisboa: Edições 70, 2004.

BERTERO, C. O.; CALDAS, M. P., WOOD JR., T. Critérios de avaliação da produção científica em administração no Brasil. Relatório de pesquisa. São Paulo: NPP/EAESP-FGV, 1998.

BORINI, F. M; OLIVEIRA JUNIOR, M. de M.; GUEVARA, A. J. H. Proposição de uma tipologia das subsidiárias estrangeiras no Brasil: resultados de evidências empíricas. In: ENCONTRO DA ASSOCIAÇÃO NACIONAL DE PÓS-GRADUAÇÃO EM ADMINISTRAÇÃO, 29. Anais... Brasília. EnANPAD. 2005. CD.

CÂMPELO, A. F; ALMEIDA, A. M. B. É possível desenvolver habilidades de intraempreendedorismo em estágios supervisionados? Analisando uma proposta de aproximação teórico-empírica. In: ENCONTRO DE ENSINO E PESQUISA EM ADMINISTRAÇÃO E CONTABILIDADE, 1, Anais... Recife. EnEPQ/ANPAD. 2007.

CARDOSO, O. de O; BARINI FILHO, U. A abordagem cognitiva na formação da competência empreendedora: caso da Odebrecht. In: ENCONTRO DA ASSOCIAÇÃO NACIONAL DE PÓS-GRADUAÇÃO EM ADMINISTRAÇÃO, 27. Anais... Atibaia: EnANPAD/ANPAD. 2003. CD.

CHIEH, N.; ANDREASSI. Intraempreendedorismo: um estudo de caso sobre o entendimento e a aplicação dos fundamentos organizacionais associados ao termo. In: ENCONTRO DA ASSOCIAÇÃO NACIONAL DE PÓSGRADUAÇÃO EM ADMINISTRAÇÃO, 31. Anais... Rio de Janeiro. EnANPAD/ANPAD. 2007. CD.

COZZI, A.; ARRUDA, C. Desenvolvimento a capacidade empreendedora de uma organização. In: ENCONTRO DE ESTUDOS ORGANIZACIONAIS, 3. Anais... Atibaia. EnEO/ANPAD. 2004. CD.

DELLAGNELLO, E. H. L. Novas formas organizacionais: ruptura com o modelo burocrático? Florianópolis, 2000. 179f. Tese (Doutorado em Engenharia da Produção), Centro Tecnológico. Universidade Federal de Santa Catarina.

DORNELAS, J. C. Empreendedorismo corporativo. São Paulo: Campus, 2003.

DURKHEIM, E. As regras do método sociológico: texto integral. São Paulo: Martin Claret, 2002.

EMMENDOERFER, M. L. A estratégia e o planejamento como pilares da cultura empreendedora: um trabalho teórico na perspectiva brasileira. Revista Qualit@as (UEPB), v. 7, n. 1, p. 9, 2008. 
EMMENDOERFER, M. L. As transformações na esfera do trabalho no final do século XX. Florianópolis, 2000. 53f. Monografia (Prêmio Senador Milton Campos 2000). Fundação Milton Campos - Conselho de Reitores das Universidades Brasileiras, 2000.

EMMENDOERFER, M. L. Controle do tempo: a percepção dos atores gerenciais da Usiminas S.A. Florianópolis, 2004. 205f. Dissertação (Mestrado em Administração). Programa de Pós-Graduação em Administração. Universidade Federal de Santa Catarina - UFSC.

EMMENDOERFER, M. L. Geração de idéias e tempo livre: o caso da Imaginarium. Florianópolis, 2002. $214 f$. Monografia (Curso de Graduação em Administração). Centro Socioeconômico. Universidade Federal de Santa Catarina.

EMMENDOERFER, M. L.; COLAÇO, P.; PEREIRA, M. F. Evidências e reflexões para a cultura do empreendedorismo e inovação nas organizações: um estudo teórico-empírico sobre a estratégia do tempo livre. In: ENCONTRO ANUAL DA ASSOCIAÇÃO DE CURSOS DE GRADUAÇÃO EM ADMINISTRAÇÃO, 17., 2006 , São Luis. Anais... ANGRAD, 2006.

EMMENDOERFER, M. L.; VALADARES, J. L.; BALBI, R. V. Esforços para a construção do conhecimento sobre "empreendedorismo interno": reflexões e perspectivas a partir de eventos da ANPAD (1997-2007). In: SIMPÓSIO DE GESTÃO DA INOVAÇÃO TECNOLÓGICA, 25. Anais... Brasília (DF). SIMPÓSIO/ANPAD. 2008. CD.

EPSTEIN, J. H. “Making sense of science: the rise of meta-analysis". Book review. The Futurist, v. 32, n. 2, 1998 , p. 44-45.

FILION, L. J, Entendendo os intra-empreendedores como visionistas, Revista de Negócio, FURB, v.9, n.2, abril/junho, 2004 (edição especial empreendedorismo).

GARCÊS, M. G; SBRAGIA, R. As estratégias de empreendedorismo corporativo interno por desenvolvimento de mercados e os fatores críticos do sucesso. In: ENCONTRO DA ASSOCIAÇÃO NACIONAL DE PÓSGRADUAÇÃO EM ADMINISTRAÇÃO, 30. Anais... Salvador. EnANPAD. 2006. CD.

GUIMARÃES, T. B. C; MACHADO-DA-SILVA, C. L. Empreendedorismo corporativo e comportamento estratégico: estudo de caso. In: SIMPÓSIO DE GESTÃO DA INOVAÇÃO TECNOLÓGICA, 24. Anais... Gramado. SIMPÓSIO/ANPAD. 2006. CD.

HASHIMOTO, M. Espírito Empreendedor nas organizações. São Paulo: Saraiva, 2006.

HISRICH, R. D.; PETERS, M. P. Empreendedorismo. 5. ed. Porto Alegre: Bookman, 2004.

HUNT, M. How science takes stock. New York: Russell Sage Foundation, 1997.

IRELAND, R. D., COVIN, J. G.; KURATKO, D. F. Conceptualizing corporate entrepreneurship strategy. Entrepreneurship Theory and Practice, v. 33, n. 1, p. 19-46, jan., 2009. doi:10.1111/j.15406520.2008.00279.x

MACHADO-DA-SILVA, C.; CARNEIRO DA CUNHA, V.; AMBONI, N. Organizações: o estado da arte da produção acadêmica no Brasil. In: ENCONTRO ANUAL DA ASSOCIAÇÃO NACIONAL DE PÓS-GRADUAÇÃO EM ADMINISTRAÇÃO, 14, 1990. Anais. Belo Horizonte: ANPAD, 1990. p. 11-28. v. 6 (Organizações).

MALLMANN, T. D. M; BORBA, B. W; RUPPENTHAL, J. E. Avaliação as tipologia dos empreendedores residentes de incubadoras utilizando o teste "Kersey Temperament Sorter". O caso da incubadora tecnológica se Santa Maria. In: ENCONTRO DA ASSOCIAÇÂO NACIONAL DE PÓS-GRADUAÇÃO EM ADMINISTRAÇÃO, 29. Anais... Brasília: EnANPAD/ANPAD. 2005. CD.

MINTZBERG, H. Criando organizações eficazes. São Paulo : Atlas, 1995.

MINTZBERG, H.; QUINN, J. B. O processo da estratégia. 3. ed. Porto Alegre: Bookman, 2001.

OAKLEY, K. Not so cool Britannia: The role of the creative industries en economic development. International Journal of Cultural Studies, v. 7, n.1, p.67-77, mar., 2004. doi:10.1177/1367877904040606.

PESSOA, E.; GONÇALVES, S. M. G. Administração empreendedora: uma abordagem comportamental. In: ENCONTRO DA ASSOCIAÇÃO NACIONAL DE PÓS-GRADUAÇÃO EM ADMINISTRAÇÃO, 28. Anais... Curitiba. EnANPAD/ANPAD. 2004. CD.

PHAN, P. H. Corporate entrepreneurship: Current research and future directions, Journal of Business Venturing, v. 24, n. 3, p. 197-205, may, 2009. doi:10.1016/j.jbusvent.2009.01.007

PINCHOT III, G. Intrapreneuring. São Paulo: Harbra, 1989.

SANTOS, P. N. dos; LEZANA, Á. G. R. As características do comportamento do intraempreendedor. In: ENCONTRO NACIONAL DE EMPREENDEDORISMO, 3., 2001, Florianópolis. Anais... Florianópolis: [ S. n.]. CDROM. 
SEIFFERT, P. Q. Empreendendo novos negócios em corporações: estratégias, processo e melhores práticas. São Paulo: Atlas, 2005.

SEQUEIRA, S. V. Intraempreendedorismo em organizações não-governamentais como prática de gestão e como legitimação: estudo de caso da ONG REFAZER. In: ENCONTRO DA ASSOCIAÇÃO NACIONAL DE PÓSGRADUAÇÃO EM ADMINISTRAÇÃO, 29. Anais. Brasília: EnANPAD/ANPAD. 2005. CD.

STONER, J. A. F.; FREEMAN, R. E. Administração. 5. ed. Rio de Janeiro: LTC, 1994.

THOMPSON, J. D. Organizations in action. New York: McGraw-Hill, 1967.

UNCTAD - UNITED NATIONS CONFERENCE ON TRADE AND DEVELOPMENT. Empretec. On-line. Disponível em: <http://www.unctad.org>. Acesso em: jun. 2008.

URICCHIO, W. Beyond the great divide: Collaborative networks and the challenge to dominant conceptions of creative industries. International Journal of Cultural Studies, v. 7, n.1, p.79-90, Mar., 2004. doi:10.1177/1367877904040607

VALADARES, J. L.; EMMENDOERFER, M. L.; Existem diferenças comportamentais entre empreendedor corporativo e intraempreendedor? In: ENCONTRO MINEIRO DE ENGENHARIA DE PRODUÇÃO, 5. Anais... Viçosa/MG. EMEPRO. 2009. CD.

VAN DE VEN, A. H. Central problems in the management of innovation. Management Science, v. $32, n .5$, may, 1986. doi:10.1287/mnsc.32.5.590

WEBER, M. Economia e sociedade. 4. ed. Brasília: UnB, 2004. 2v.

WOOD JR., T.; BENDASSOLLI, P. F.; KIRSCHBAUM, C.; PINA E CUNHA, M. (Coord.). Indústrias criativas no Brasil. São Paulo: Atlas, 2009.

ZIMMER, P.; HOELTGEBAUM, M. Um estudo sobre a empregabilidade dos funcionários de uma estatal. In: ENCONTRO DE ESTUDOS ORGANIZACIONAIS, 3, Anais... São Paulo: EnEO/ANPAD, 2004. CD. 